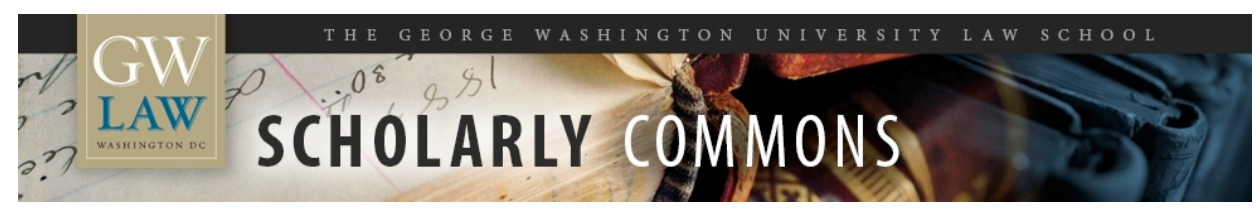

GW Law Faculty Publications \& Other Works

Faculty Scholarship

2005

\title{
Trial by Market: A Thought Experiment
}

Michael B. Abramowicz

George Washington University Law School, abramowicz@law.gwu.edu

Follow this and additional works at: https://scholarship.law.gwu.edu/faculty_publications

Part of the Law Commons

\section{Recommended Citation}

Abramowicz, Michael B., "Trial by Market: A Thought Experiment" (2005). GW Law Faculty Publications \& Other Works. 229.

https://scholarship.law.gwu.edu/faculty_publications/229

This Article is brought to you for free and open access by the Faculty Scholarship at Scholarly Commons. It has been accepted for inclusion in GW Law Faculty Publications \& Other Works by an authorized administrator of Scholarly Commons. For more information, please contact spagel@law.gwu.edu. 


\section{Trial by Market: A Thought Experiment}

\section{By Michael Abramowicz ${ }^{*}$}

This Article considers the possibility of providing incentives to judges to decide cases in the same way that an appellate panel would decide them. Random selection of a proportion of cases for retrial could be used to encourage judges to place aside their preferences in deference to the perceived preferences of a majority of judges. Providing such incentives to judges may reduce the need for alternative approaches to reducing judicial discretion, such as substantive law based on rules rather than on discretion. An information market similarly could be used to accomplish the task of adjudication, with some cases randomly selected for traditional adjudication to discipline the information market participants. Such an approach may be more costefficient than provision of monetary incentives to judges where information is widely dispersed, or where it is impractical for the government to hire enough judges to handle a large group of cases. Advantages and disadvantages of these approaches are discussed.

The monetary compensation of a judge generally does not depend on how the judge resolves any given case. ${ }^{1}$ This regime might appear to be indispensable to an independent judiciary. If judges were paid based on how well they resolve cases, then some institution might be used to rate each judge's performance, and judges might decide cases based on the perceived preferences of those acting on behalf of that institution. In theory, however, it would be possible for judges even in an independent judiciary to be compensated on the basis of the decisions that they reach, as long as no subjective ratings of judicial performance were to come from outside the judiciary itself.

For example, a statute might specify that a judge's compensation shall include a component that depends on objective measures of the judge's performance. Such measures might include the number of cases that the judge has heard and the frequency with which an appellate

\footnotetext{
* Associate Professor, George Washington University Law School.

${ }^{1}$ See, for example, 28 U.S.C. $§ 455(b)(4)$ (2000) (forbidding a judge from participating a case in which he or she has a direct financial interest). The incentives that determine how judges will decide cases are thus nonmonetary. See Posner (1993, p. 2) ("Almost the whole thrust of the rules governing compensation and other terms and conditions of judicial employment is to divorce judicial action from incentives - to take away the carrots and sticks, the different benefits and costs associated with different behaviors, that determine human action in an economic model.”).
} 
court reversed the judge. ${ }^{2}$ Presumably, in such a regime, judges would have stronger incentives to resolve cases expeditiously and to do so without making potentially reversible errors. The puzzle thus arises: Why aren't judges compensated based on their performance?

Part I addresses this question by offering a simple model of a judicial system in which judges receive performance-based incentives. In this system, a small percentage of cases are randomly selected for retrial, and judges are compensated based on the results on retrial of cases over which they presided. The model illustrates the benefits of an incentive-based judicial compensation system, as well as some of its drawbacks. Incentives may discourage judges from resolving cases based on their idiosyncratic preferences. In addition, incentives may make rigid procedural rules less necessary and also may increase the attractiveness of discretion relative to rules in substantive law. On the other hand, incentive-based compensation increases judges' uncertainty about how much income they will earn in any given time period.

The model of Part I retains the assumption that judges are chosen through some process of social choice, such as appointment or election. If judges can be given monetary incentives to resolve cases as other judges would resolve them, however, then presumably third parties could be given incentives to resolve cases as judges would resolve them. Appointment and election processes serve as a screen that seeks to ensure that judges will resolve cases as society wishes, so providing financial incentives could reduce the importance of such a screen. It is thus possible to imagine a judicial system consisting of a very small number of public judges, whose function effectively is to discipline a much larger group of mercenary private judges.

Part II describes an approach to creating such a system that would allow for private prediction without requiring the government to screen third parties at all to determine who can conduct an adjudication. The system would use an information market to evaluate a case. The third-party predictors in such a market would be compensated based on the results in a percentage of cases randomly selected after the close of the information market for traditional adjudication. The remaining cases would be resolved by the information market prediction. Part II briefly identifies some of the advantages and concerns about implementation of such a market.

\footnotetext{
${ }^{2}$ For an analysis using such measures to rate sitting U.S. federal appellate judges, see Choi and Gulati (2004).
} 


\section{MONETARY INCENTIVES FOR JUDGES}

Perhaps the simplest criterion that might be used to evaluate trial judges would be the judges' reversal rates. A regime that compensated judges based on this rate, however, might lead judges to resolve cases in a manner that would minimize the possibility of reversal, for example by resolving cases on the facts rather than on the law. For a compensation system to serve effectively without changing judicial incentives, it would need to have some means of reviewing judges' decisions on factual issues as well as legal issues.

A solution is for the appellate court to rehear a case in its entirety, reconsidering both factual and legal issues de novo. If appellate courts did this in our present judicial system, the district court decision would be of no greater moment than a nonbinding arbitration. Limitation of the types of issues that appellate courts may consider is thus a practical approach in a regime in which all cases can be appealed. ${ }^{3}$ It might be possible, however, to have appeals only for a subset of cases randomly selected after the trial court decision for full de novo review. Trial court decisions would thus still matter for many cases. Trial judges could then be graded based on the subset of cases randomly selected for appeal. The trial judges' incentive would be to resolve cases as closely as possible to how the appellate court would resolve them, rather than to decide the cases on the facts to avoid review of law.

Consider, for example, the following system: A case is randomly assigned to a trial judge, who resolves the case, either by imposing or denying liability. With some probability, the case would be randomly selected for trial by the appellate court. If the appellate court reached the same resolution as the trial judge, then the trial judge would receive some increment to base compensation.

Of course, most cases involve more than a single binary choice. A case might have two binary issues, such as whether the plaintiff has standing and whether the plaintiff is entitled to relief, as well as a question of damages should the plaintiff prevail. A more elaborate system could accommodate that. For example, the system might result in some cases being randomly selected for redeterminations of damages. The trial judge's salary increment would then depend on how close the trial judge was to the appellate court's damages determination. These design

\footnotetext{
${ }^{3}$ For a model explaining deferential review of trial court fact-finding, see Drahozal (1998).
} 
details are beyond my scope, however, and I will for analytical convenience adhere for now to a case presenting a single issue with a binary resolution.

Section I.A offers a simple formal model of this system, showing that an increase in compensation will make trial judges more likely to decide cases as the appellate court would decide them. Section I.B assesses whether reducing the effect of idiosyncratic judicial preference should count as a benefit or a cost, offering an informal argument and a formal one to describe the benefits of reducing idiosyncratic preferences, and then an informal assessment of the costs. Section I.C examines the consequences of a compensation system for judicial work, considering both static and dynamic effects.

\section{A. A Model of Incentivized Judging}

Suppose that a judge cares about three things: not wanting to resolve a case in a manner contrary to how the majority would resolve it (with the strength of this concern proportional to the proportion of all judges who would resolve the case in the same way), resolving a case according to the judge's idiosyncratic preference, and minimizing the work it takes to resolve a case. More formally, we construct a loss function for a judge who must decide whether to impose liability $(l=1)$ or not to impose liability $(l=0)$. Let $\alpha, \beta$, and $\gamma$ be parameters, where $\alpha, \gamma>0$, and $\beta$ can be either positive or negative; let $p$ be the probability that the appellate panel would impose liability if hearing the case de novo; and let $w$ be a variable representing the amount of work the judge decides to perform. The loss function can thus be represented as:

$$
L=\alpha|l-p|+\beta(1-l)+\gamma w .
$$

If $\beta>0$, then the judge has a personal preference to impose liability, and if $\beta<0$, the judge has a personal preference not to impose liability. Either way, that personal preference may yield where the judge concludes that most appellate judges would resolve the case in the opposite way.

This is, of course, a vastly simplified model of judging. It captures, however, that judges generally seek to avoid reversal and that they may have personal preferences as to how to resolve a particular case. It also demonstrates that different judges may have different personal preferences, and may attach different weights to the costs of reversal and of deciding cases contrary to their personal preferences. 
For a given level of work, the judge chooses $l$ to minimize $L$, given the judge's estimate $p^{\prime}$ of $p$. Thus, the judge will choose $l=1$ if $L_{l=1}<L_{l=0}$, i.e. $\alpha\left(l-p^{\prime}\right)<\alpha p^{\prime}+\beta$. It follows that the judge imposes liability where $p^{\prime}>(\alpha-\beta) / 2 \alpha$.

The provision of monetary incentives to judges effectively increases $\alpha$. It is possible, of course, that very small monetary incentives might lead judges to count reversal as less of a cost, because they wish to demonstrate their independence and lack of concern for money. Presumably, though, at some level of incentives, judges will respond to those incentives, and I will assume that incentives are sufficiently high that the incentives increase $\alpha$. The higher the value of $\alpha$, the closer $(\alpha-\beta) / 2 \alpha$ to $1 / 2$. The conclusion is thus entirely unsurprising: Providing judges with monetary rewards in cases that they decide the same way as the appellate panel will make judges more likely to decide those cases as they expect the majority of appellate panels to decide them.

\section{B. The Benefits and Costs of Conformity}

\section{Benefits: An Informal Argument}

Monetary incentives would thus tend to induce conformity of trial judges to the perceived majority of appellate judges. Is this a desirable consequence? A simple argument that this is a benefit follows from the Condorcet Jury Theorem. ${ }^{4}$ Suppose that we believe that, at least in general, each of a group of people independently considering a problem has a greater than even chance of reaching the correct view on a particular question. Then, the greater the group, the greater the probability that a majority of the group reaches the correct answer.

The theorem has a straightforward application to legal process. To be sure, in law we must acknowledge the caveat that answers may not be objectively correct or incorrect. But the same logic still applies. Start with two assumptions: first, that for at least some legal issues a "better" answer exists, even if cannot be objectively ascertained with certainty; and second, that a randomly selected judge is more likely to arrive at this answer than its opposite, even though personal preferences may affect that judge's decision. These are minimal assumptions, for if they fail to hold, it is hard to justify the use of human judges rather than coin flips. The Condorcet

\footnotetext{
${ }^{4}$ For a general discussion, see Grofman (1978).
} 
conclusion is that the resolution of a larger panel of judges should be preferred to the resolution of a single judge. ${ }^{5}$

Two additional assumptions are needed here to make the argument from Condorcet complete. First, we must assume that an individual judge's estimate of the proportion of judges who would impose liability will generally be closer to the actual proportion than the judge's own preferred resolution (zero or one) would be. That is, a judge must have some minimal ability, at least after working on a case, to estimate how many appellate judges would reach one resolution or another. Second, we must assume that the trial judges are not superior to the appellate judges in achieving a better resolution of the case. Given these assumptions, monetary incentives provide a social benefit by reducing the proportion of cases in which judges decide to resolve the cases in accord with the judges' personal preferences rather than in accord with the anticipated resolutions of a majority of appellate judges.

This reasoning may apply even in a context in which what is important is not a legal decision itself, but rather the anticipation of legal decisions by private parties. Consider, for example, a strict liability tort regime, and suppose that there are some cases in which it will be unclear whether the defendant caused the plaintiff's injury. Assume that ninety percent of judges in this group of cases would conclude that the defendant caused the plaintiff's injury, while ten percent of judges would conclude that the defendant did not cause the injury but recognize that they are in the minority. Is it preferable to have a legal regime that would lead all judges to impose liability, or one that would result in ninety percent of judges imposing liability? Monetary incentives would push the legal system closer to the former.

In the regime in which all judges would impose liability, potential defendants in such cases will internalize the full extent of injuries in such cases, even though there are some who believe that the defendants did not cause such injuries. In the regime in which only ninety percent of judges would impose liability, potential defendants would internalize ninety percent of the injuries. The only difference is thus the question of whether, after potential defendants have internalized ninety percent of the injuries, whether it is socially beneficial for the potential defendants to internalize the additional ten percent of the injuries. Assuming that all judges agree that it is socially beneficial for potential defendants to internalize all of the injuries that they

\footnotetext{
${ }^{5}$ For an application of the Condorcet Jury Theorem to the size of appellate panels, see Kornhauser and Sager (1986, pp. 97-98).
} 
cause, ninety percent of judges would think it desirable for the potential defendants to internalize the additional ten percent of the injuries, because those judges would believe that the defendants actually caused the injuries. If each judge is more likely to be right than wrong on this question, there is at least a fifty percent chance (presumably, much greater) that potential defendants should internalize the additional ten percent of the injuries. Thus, the regime in which all judges impose damages is superior to one in which only ninety percent of judges impose damages.

This argument is parallel to Coons (1964)'s defense of the preponderance-of-theevidence standard in civil cases. Coons asks whether it makes sense to impose full liability on a defendant when the fact-finder concludes that there is a greater-than-fifty-percent chance that the defendant in fact caused the plaintiff's injury, and no liability when the fact-finder concludes that there is a less-than-fifty-percent chance. Coons defends the discontinuity in the liability function by comparing it to an alternative liability function in which damages are multiplied by the factfinder's estimate of the probability of causation. Once damages proportional to the probability of causation are awarded in a case in which the probability estimate is greater than fifty percent, there is still greater than a fifty percent chance that the additional damages should be imposed. The argument here moves Coons's argument to a higher level of abstraction, with the probability that a case is decided correctly derived from various judges' recommended outcomes rather than from a single fact-finder.

The argument is perhaps easiest to understand using an extreme example and focusing on a single case. Suppose in a lawsuit between $A$ and $B, 99 \%$ of judges would rule for $A$. Let us assume that there is a correct, or at least a better, answer. There is a chance, of course, that the $1 \%$ minority of judges are in fact correct, but from the disproportion, the chance would appear to be small. The incentivized judges issue is irrelevant $99 \%$ of the time, so to evaluate the argument, we must consider the $1 \%$ of situations in which the case happens to be assigned to a judge who adopts the minority position. Will this case more likely be resolved correctly if these judges follow their own opinion, or the dominant opinion? Because the minority position is probably wrong, the resolution will be more likely to be correct if the minority judges place aside their own views. Of course, the same analysis applies, albeit less strongly, when judges are more evenly divided. If the goal is to resolve a case correctly, majority resolution is best. 
For those still skeptical, consider the following question: Should legislatures work according to lottery voting? That is, should we randomly select the vote of a single legislator on any particular issue? Even placing aside the problem that legislative resolutions would cycle, the proposal seems normatively unattractive, and those who have discussed lottery voting have imagined using it to construct the legislature rather than to resolve discrete issues being considered. ${ }^{6}$ The issue is less salient in the judicial context, because when a judge resolves an issue we do not necessarily whether a majority of judges would reach the opposing resolution, but the reasoning is the same. A court resolving an issue of law is more likely to resolve that issue properly when it resolves it in the way that most judges would resolve it than when it resolves it in the way that most judges would reject. Similarly, to the extent that a judge engages in fact-finding, a judge who interprets the facts of a case in that most other judges faced with the same facts would reject is, more likely than not, interpreting the facts incorrectly.

\section{Benefits: A Formal Argument}

It is straightforward to formalize the argument that it is beneficial to provide judges with incentives to act as the majority of judges would decide cases. Consider a universe of cases to be tried by the judicial system. In each case, assume that there is a correct answer, either that liability should be imposed or that it should not be imposed. Of course, we do not assume that anyone knows what this correct answer is. In addition, for each case, some proportion $p$ of judges, if acting without monetary incentives, would impose liability. We define a "pure monetary incentives" condition to be one in which judges will always decide a case as the majority of judges would resolve that case, i.e. to find liability if and only if $p>0.5$. We will initially compare error costs in the no incentives condition with those in the perfect incentives condition, and then turn to a regime in between the extremes.

To compare the error costs, consider separately the two groups of cases, those in which the correct answer is to impose liability, and those in which the correct answer is not to impose liability. Let $n(p)$ represent the expected distribution of the cases in which the correct answer is to impose liability, and $n^{\prime}(p)$ represent the expected distribution of the cases in which the correct answer is not to impose liability. We assume that where $0<=p<0.5, n(1-p)>n(p)$. This is a

\footnotetext{
${ }^{6}$ See, e.g., Amar (1995).
} 
fairly minimal rationality assumption, allowing for the possibility that there will be cases in which a majority of judges will reach the wrong answer. The assumption means only, for example, that in the universe of cases for which the correct answer is liability, there will be a larger number of cases in which $90 \%$ of judges would impose liability than in which $10 \%$ of judges would impose liability. This assumption would entail, among others, a normal distribution with mean to the right of 0.5 (cut off at the 0 and 1 extremes). Meanwhile, we will make the opposite assumption for the cases in which the correct answer is not to impose liability: Where 0 $<=p<0.5, n^{\prime}(1-p)<n^{\prime}(p)$.

We also must offer some simple assumptions regarding the cost of errors. For the group of cases in which the correct answer is to impose liability, a failure to impose any liability imposes a cost of $c$, and for the group of cases in which the correct answer is not to impose liability, imposition of liability imposes a cost of $c^{\prime}$. (Without loss of generality, we could allow for variation in $c$ and $c^{\prime}$ across cases, as long as the expected distribution of cases corresponding to any particular value of $c$ or $c^{\prime}$ met the above assumptions regarding $n$ or $n^{\prime}$.) For example, if in a group of cases, the correct answer is to impose liability but liability will be imposed only $30 \%$ of the time, then the average error cost per case will be $0.7 c$.

We can now compare total error costs in the no incentives condition $\left(E C_{N I}\right)$ with total error costs in the perfect incentives condition $\left(E C_{P I}\right)$. Let us for now consider only the cases in which the correct answer is to impose liability, and ignore the cases in which the correct answer is not to impose liability. In the no incentives condition, for cases where $p$ of judges would impose liability, the average error cost will be equal to $c(1-p)$. In the pure incentives condition, there will be no error costs for $0.5<=p<=1$; when $p<0.5$, however, no liability will be imposed, and the full error cost of $c$ will be borne. Thus, we can represent the error costs for the cases in which the correct answer is to impose liability as follows:

$$
\begin{aligned}
& E C_{N I}=\int_{0}^{1} c(1-p) n(p) d p . \\
& E C_{P I}=\int_{0}^{0.5} c n(p) d p .
\end{aligned}
$$

The pure incentives condition reduces error costs if and only if $E C_{P I}<E C_{N I}$, which can be rearranged to

$$
\int_{0}^{0.5} c p n(p) d p<\int_{0.5}^{1} c(1-p) n(p) d p
$$

By application of the Chain Rule, this is equivalent to 


$$
\int_{0}^{0.5} c p n(p) d p<\int_{0}^{0.5} c p n(1-p) d p
$$

This inequality must hold, as a result of our assumption that where $0<=p<0.5, n(1-p)>n(p)$. Thus, the pure incentives condition reduces error costs in the cases in which the answer is to impose liability.

Parallel logic can be used to show that the pure incentives condition also reduces error costs relative to the no incentives condition for the cases in which the correct answer is not to impose liability. Thus, regardless of the proportion of cases in which the correct answer is to impose liability, for the entire universe of cases, the pure incentives condition reduces error costs relative to the no incentives condition.

We could also define an incomplete incentives condition as one in which a judge will act like judges in the perfect incentives condition with probability $\theta$, and like judges in the no incentives condition with probability $1-\theta$. It follows that $E C_{I I}=\theta E C_{P I}+(1-\theta) E C_{N I}$, and thus that for $\theta>0, E C_{I I}<E C_{N I}$. Thus, under the assumptions above, over the universe of cases, incomplete monetary incentives will reduce error costs relative to no monetary incentives.

\section{Costs}

The most obvious argument against inducing greater conformity of judges to perceived majority resolutions is that manifest disagreement may itself have some benefit. The "percolation" of issues among disagreeing judges may increase the possibility that an authoritative decisionmaker, such as a higher court or the legislature, will reach the correct resolution of the issue. It may sometimes be useful for trial judges to challenge the opinions of appellate judges, and perhaps in the long run to change those opinions.

More generally, a regime with monetary incentives might affect judges' willingness to write opinions explaining their decisions. Perhaps monetary incentives might make judges less interested in writing opinions because they are more concerned about simply determining how majorities would resolve cases, or perhaps they would be more interested in writing opinions because they wish to convince appellate panels that they have resolved cases correctly.

My purpose, of course, is not to suggest that greater judicial conformity to the majority of appellate panels is always desirable, let alone that monetary incentives are always desirable. I have not even considered the effect of monetary incentives on the perceived legitimacy of the courts or assessed whether such legitimacy matters. My central point, however, is that there is at 
least an argument for reducing the influence of idiosyncratic judicial preference on individual cases. Treating like cases alike is not merely more fair than randomly deviating in some cases, it also may be more efficient. Paying judges to act as the majority of judges are expected to act is one way of increasing the proportion of like cases that are treated alike. If one goal of a system for resolving a certain class of disputes is to reduce the proportion of cases affected by idiosyncratic preference, then incentivizing judges to act as the majority may help in some contexts.

\section{Effects on the Judicial Process}

The more a judge works on a given case, the better is likely to be the judge's estimate of the proportion of judges who would impose liability. As indicated above, increased monetary incentives should push the threshold above which the judge imposes liability closer to $1 / 2$. A judge may work harder in a regime with more monetary incentives, because the judge may care more once provided with incentives (that is, total loss is higher in a regime with greater incentives), and because there may be more cases in which additional work might affect the decision the judge reaches. ${ }^{7}$

The legal system currently uses means other than monetary incentives to prevent shirking by judges. One possible justification of many rules and norms of judicial procedure, such as the requirement that judges hear testimony when there are genuine issues of material fact, ${ }^{8}$ is that these requirement increase judicial work effort. If a judge could resolve a case pretrial when the judge personally believed that testimony would not make a difference, then a judge might be tempted to resolve cases pretrial even when the judge recognized that testimony might affect the judge's ultimate decision. The use of a relatively objective summary judgment standard, rather than a subjective standard, helps prevent judicial shirking. This benefit comes at some cost, however, in cases where live testimony in fact would not make a difference.

Such rules and norms may become less necessary once judges are given monetary incentives. Consider, for example, a legal system that adjudicates disability claims, and assume

\footnotetext{
${ }^{7}$ This conclusion depends, of course, on the probability distribution of cases. Suppose a judge in a regime without monetary incentives would impose liability only when the judge's estimate of the proportion of judges who would do so exceeds 0.9 , but the judge would impose liability in a regime with monetary incentives when the judge's estimate of the proportion exceeds 0.6 . If there are many cases in which the judge's estimate is around 0.9 and comparatively few in which the estimate is around 0.6 , then a judge may work less hard in a regime with monetary incentives.

${ }^{8}$ See, for example, FED. R. CIV. P. R. 56 (providing the summary judgment standard).
} 
for now that the facts of such cases are so varied that the assessment of whether an applicant is disabled ultimately must be a discretionary one. As the Supreme Court noted in Matthews $v$. Eldridge, ${ }^{9}$ one argument for providing a right to an oral hearing in such cases is that such a hearing may reduce the probability of an erroneous disposition. This argument presumably does not apply in cases in which a decisionmaker is genuinely sure in advance of an oral hearing of the eventual decision, but a decisionmaker might falsely claim to be sure of the eventual decision if such a claim would allow the decisionmaker not to hold a hearing. A right to a hearing may be a second-best solution in a world in which we cannot verify whether a decisionmaker truly believes that a hearing would not make a difference. But monetary incentives will tend to provide decisionmakers with incentives for further inquiry if and only if that inquiry in fact might make a difference. Thus, an adjudicative system with monetary incentives for judges should tend to afford decisionmakers more procedural discretion than an adjudicative system without monetary incentives.

The same is true with regard to substantive discretion. One justification for a system of rules rather than a system of judicial discretion is that rules reduce the possibility of idiosyncratic preference affecting case results. Shavell (2004) models adjudication as an agency problem, in which the judge as agent may choose to act on his own ideological beliefs rather than those of the principal, society at large. A familiar drawback of rules is that they are overinclusive and underinclusive, and thus that they may misrepresent what the preference of society would be in a discretionary regime. If the appellate judiciary as a whole is more representative of the views of society as a whole than any randomly selected trial judge (or than any randomly selected appellate panel), then monetary incentives may tend to lead judges to act more in accordance with the preferences of society than they otherwise would. Thus, monetary incentives and rulebased substantive law may be two alternative means of inducing judges to act as society would prefer. In a regime with monetary incentives, rules are less necessary. It may thus be possible for the legal system to achieve the best of both worlds: discretion that allows close tailoring to the facts of cases, as well as relatively consistent treatment across decisionmakers.

Once again, considering a system of disability adjudication can make this point clearer. Suppose that it is in fact possible to develop a rule-based system of disability payments, but such

\footnotetext{
${ }^{9} 424$ U.S. 319, 335 (1976).
} 
a system would lead to results in some subset of cases that most people (and judges) would believe to be contrary to the goals of the program. Such a rule-based system might nonetheless be preferable to a system that afforded judicial discretion, for example if a large percentage of judges in a discretionary system would often rule based on their own beliefs about economic distribution independent of the facts of any particular case. But if the median appellate judge provides a reasonably close proxy for the social consensus on disability, then monetary incentives might lead judges in a discretionary regime largely to ignore their individual political preferences. So, the disability system could allow discretion yet discourage ideological decisionmaking.

Finally, let us consider briefly the effects of monetary incentives on the composition of the judiciary itself. The regime might affect the reputation of the judiciary and therefore affect the willingness of talented lawyers to serve in it. If judges are seen as mere mercenaries, then lawyers might be less willing to serve. On the other hand, if the regime in fact reduced idiosyncratic judging, the reputation of the judiciary could rise, and lawyers might be more willing to serve.

A system of monetary incentives also might change the number of judges necessary to populate the judiciary. Once again, there are competing effects. If appellate adjudication now requires rehearing of the facts as well as consideration of issues of law, more appellate judges might be needed. But because only some cases would be randomly selected for appeal, fewer judges might be needed.

Self-selection by lawyers might affect the quality of the judiciary. Presumably, more talented lawyers will better understand cases and thus be better able to predict how appellate panels will resolve these cases. These lawyers should thus be more willing to serve than lawyers with lesser talents, assuming that lawyers have some information about how successful they are likely to be.

Perhaps the most significant effect, however, would be to discourage judicial service as a result of the increase in the variance of expected compensation, even assuming that average expected compensation remains constant. This variance could be quite high, especially if only a small number of a judge's cases in any given year are reviewed. A judge's compensation would depend not only on how successful the judge was at estimating the proportion of appellate panels 
that would impose liability, but also on which cases happened to be chosen for review and on which panels happened to be chosen to review those cases. One answer to the question of why judges do not receive performance incentives is thus the same answer to the question of why many employees who receive annual salaries do not receive performance incentives: the increased risk that accompanies such incentives can reduce the attractiveness of the overall compensation package.

\section{INFORMATION MARKET-BASED ADJUDICATION}

Part I has described one mechanism by which trial judges could be given incentives to predict decisions of appellate judges. The mechanism belongs to a broad class of mechanisms called "scoring rules," and it has long been recognized that scoring rules can be used to provide parties with incentives to make accurate predictions. ${ }^{10}$ There is, however, an alternative technology for encouraging accurate predictions: information markets. ${ }^{11}$ Information markets have been shown to be accurate predictors in a range of settings. ${ }^{12}$ Unlike scoring rules, information markets aggregate the predictions of multiple predictors and thus can incorporate dispersed information.

A simple information market might be used to predict a binary judicial decision as follows: For \$1, anyone could purchase two shares, one corresponding to liability and one corresponding to nonliability. Once the case were tried, then the shares corresponding to the actual decision would be liquidated at $\$ 1$, and the shares corresponding to the reverse decision would be liquidated at $\$ 0$. At any given time, the price at which shares traded would provide a prediction of the probability that the court would find liability. Indeed, information markets like this already exist for certain high-profile cases. ${ }^{13}$

This simple information market will not be sufficient here for at least two reasons. First, as described above, the case is eventually tried. The model in Part I sought to discipline judicial decisionmaking by selecting only some portion of cases for trial. The trick is to create an information market that will work even when there is only some probability that a decision

\footnotetext{
${ }^{10}$ See, for example, Clemen (2002); and Winkler (1969).

${ }^{11}$ See, for example, Abramowicz (2004); and Hanson (1995).

12 See, for example, Berg et al. (2000); Forsythe et al. (1992).

${ }^{13}$ See, for example, www.tradesports.com (offering information markets on cases involving Martha Stewart, Michael Jackson, and Kobe Bryant).
} 
eventually will be reached. In the cases that are not randomly selected for trial, the information market prediction of a trial could be used as an alternative to the trial itself. Second, there is little incentive for anyone to participate in this market. To stimulate interest and accurate predictions, there must be some effective subsidy to the market.

Recent literature on information markets describes a mechanism that may seem more akin to traditional scoring rules than to a securities market, but the mechanism still can aggregate predictions of a number of individuals. It is straightforward to adapt this mechanism to implement a subsidized information market in which there is only some probability of a decision. Part II.A describes briefly how an information market might perform the task of adjudication. Part II.B then discusses some of the benefits and costs of such an approach.

\section{A. An Information Market for Adjudication}

An information market might be used to accomplish the task of adjudication in cases that do not settle. The market, modeled on the information market designs described in Hanson (2003) and Abramowicz (2004), could work through the following algorithm:

(1) The government would announce a market subsidy for the group of cases.

(2) For each case in the group, the government would announce 0.5 as an initial prediction of the result of adjudication. Denote this prediction $p_{0}$.

(3) The government would then auction off the right to be the next predictor, with the auction revenues added to the market subsidy. The third party winning the auction would then make a prediction $p_{1}$. (The purpose of this step is to eliminate any windfall that might exist by virtue of being the first predictor and to eliminate any race that might exist to become that predictor. ${ }^{14}$ )

(4) Other third parties could then make additional sequential predictions for some period of time, $p_{2}$ through $p_{\mathrm{n}}$. (The precise end time of the market would not be announced, to prevent interested parties from making predictions at the last instant.)

(5) With some positive probability, the case is randomly selected for traditional adjudication. In these cases, let $r=1$ if the court imposes liability and 0 otherwise. In the cases

\footnotetext{
${ }^{14}$ If there is a second-mover advantage, no one might bid to become the first predictor. To overcome this predictor, negative bids could be allowed. If the highest bid were a negative number, the bid amount would be removed from the market subsidy to pay the first predictor.
} 
not selected for traditional adjudication, market participants receive and pay nothing. ${ }^{15}$ If a case is not selected for traditional adjudication, then the last prediction controls, so liability is imposed if $p_{n}>0.5 .^{16}$ (The parties might then be given an opportunity to settle the damages issue, and if settlement fails, an information market akin to that described here could be used to determine the amount of damages.)

(6) Each predictor in the cases selected for adjudication receives a score $s_{i}$, which reflects the improvement in the prediction provided by predictor $i$ over predictor $i-1$. Thus, $s_{i}=(1-\mid r-$ $\left.p_{i} \mid\right)-\left(1-\left|r-p_{i-1}\right|\right)=\left|r-p_{i-1}\right|-\left|r-p_{\mathrm{i}}\right|$.

(7) Predictors with positive scores receive money from the government; those with negative scores pay money to the government. Let win $=$ the sum of all positive $s_{i}$ across all cases, and let lose $=$ the absolute value of the sum of all negative $s_{i}$. Then, each predictor with a negative $s_{i}$ pays the amount of the market subsidy multiplied by the absolute value of $s_{i} /$ win. The market subsidy (including the auction revenues) plus these payments are then shared among those with positive scores, so that each predictor with a positive $s_{i}$ receives the market subsidy multiplied by $\left(s_{i} / \text { win }\right)^{*}(1+($ lose / win $)){ }^{17}$

A full discussion of the mechanics of information markets is beyond the scope of this paper. Several points are worth noting, however.

Incentives to invest in research. Because predictors are rewarded for improving the previous predictions, potential predictors' incentive to invest in research on a case depends on the extent to which information is likely to allow the potential predictor to improve on the current probability assessment. Thus, the information market has the useful property of directing the government's subsidy toward those cases in which research is most likely to change initial assessments.

\footnotetext{
${ }^{15}$ Auction revenues could be removed from the market subsidy in such cases and refunded to the initial predictors. The point is not an important one, however, as net auction revenues received should be approximately the same whether the revenues are refunded are not. If, for example, in half of cases the winning bidder will lose the auction revenues and receive nothing in return, then bidders will bid only half as much.

${ }^{16}$ An alternative approach would be to impose liability in proportion to the probability of victory. For a recent proposal arguing that arbitrators should impose damages in proportion to the expected value of a reward at trial, see Joshua Davis, Expected Value Arbitration, 57 OKLA. L. ReV. 47 (2004). See also sources cited id.at 48 n.8 (discussing the possibility of compromise or probabilistic verdicts).

17 Some alternative distribution rule is needed in the unlikely event that no predictor in any case selected for traditional adjudication improved on the previous prediction. See Abramowicz (2004). The danger of this would be greatest if there were a very small number of cases and a very small number of predictors in each.
} 
Litigants' incentives to participate and to manipulate. Litigants would retain incentives to convince the participants in information markets of their positions, just as they would try to persuade judges in the model of Part I. Presumably, the information market would not eliminate the need for some discovery regime (unless an additional information market were constructed to resolve discovery disputes, with only a small percentage of discovery disputes brought to a court). Litigants, however, would naturally have some incentive to reveal requested information to alleviate suspicions of market participants. ${ }^{18}$ The presentation of evidence to the market, however, could be informal, as litigants would have incentives to present information in whatever format would be sufficient to provide information to market participants.

Litigants also might seek to participate in the information market themselves, to the extent that they believe that any trading losses that they suffer will be less than any benefit to them if the case is not randomly selected for adjudication. Other market participants, however, would have an incentive to identify such self-interested predictions and make contrary predictions. Hanson and Oprea (2004) argue that manipulation will tend not to affect information market prices, and indeed may tend to make information market prices more accurate because such attempts effectively increase the returns to informed trading. The extent to which manipulation strategies may be successful is, of course, an empirical question. Self-interested trading could simply be banned, though enforcement may be more difficult than enforcement of analogous bans on bribing judicial officials.

Proportion of cases selected for traditional adjudication. The government faces a tradeoff in determining the proportion of cases to be selected for traditional adjudication. The higher the percentage, the greater the cost of performing traditional adjudication. Participants in the information market, however, bear some risk from the uncertainty about whether a case will be selected for traditional adjudication. The more cases that are selected, the less random will be the market participants' rewards, and the more closely the participants' returns can be expected to correlate with their abilities and efforts.

If traditional adjudication is particularly expensive (for example, because of the need to have formal trial procedures), it might be possible to reduce the total cost of adjudication by having multiple information market stages. For example, ten percent of cases might be selected

\footnotetext{
${ }^{18}$ For a model of how an unraveling effect may augment voluntary incentives to reveal information, see Milgrom \& Roberts (1986).
} 
for adjudication in a second-phase information market, with an additional subsidy provided for resolution of the cases in that information market. Of those cases, ten percent might be selected for traditional adjudication. The result of the second-phase information market would be used to pay off predictors in the first-phase information market. The additional subsidy means that this approach will be more expensive than simply providing that one percent of cases should be randomly selected for adjudication. The subsidy, however, could be small, because private parties will already have had incentives to inform themselves about a case in earlier stages. The subsidy might be less than the total cost of a regime that would provide that ten percent of cases should be randomly selected for traditional adjudication. In addition, the results of a secondphase information market might be more predictable than the results of a traditional adjudication, reducing the risk to market participants.

Effect of the traditional adjudication. If the goal of this system is to reduce the influence of idiosyncratic preference on decisions, that goal will be accomplished only incompletely, because in cases randomly selected for traditional adjudication, judges may still have discretion. If this is sufficiently undesirable, the information market could be used to resolve the amount that the defendant must pay the plaintiff in all cases, including those selected for traditional adjudication. The problem, of course, is that the litigants would no longer have an incentive to participate in the traditional adjudication. Thus, the traditional adjudication would need to be not so traditional after all. For example, adjudicators might informally consider all evidence that the litigants previously presented in any form to the information market.

\section{B. Evaluating the Information Market Approach}

The benefits and costs of the information market approach are similar to the benefits and costs of providing judges monetary incentives to decide cases. Just as providing judges with monetary incentives limited the need for formal judicial procedure, an information market would not need formal procedures at all. A drawback to the approach is that participation in the information market is risky, just as judges faced risk with performance incentives, and the government effectively must pay for this risk, for example by receiving less revenue in the auctions to determine the first predictor than it would in a system with no risk. In contrast to the system of incentivized judging, participants in the information market can lose money in 
individual cases. Private parties, however, might be better able than judges to diversify risk, for example by working together in firms.

There are three significant benefits to the information market approach relative to the incentivized judging approach. First, the market eliminates the need for society to screen trial judges. Providing judges monetary incentives limited the need to screen judges, because judges would no longer be as motivated by ideological concerns, and because judges lacking ability would tend to opt not to serve. There was still some danger, however, that a judge might be willing to sacrifice income to achieve an ideologically preferred resolution. If it indeed is true that information markets will not easily be subject to manipulation, then participants in information markets will not be able to make such a tradeoff. A participant who makes a bad prediction not only may lose money, but also may see a subsequent predictor's assessment determine the outcome of the case. If, however, contrary to the initial empirical evidence, information markets are subject to manipulation, then trading would need to be restricted to a preapproved group of traders, and screening could be more expensive.

Second, and following directly from the first point, the information market is easily scalable. It can be used for a small number of cases or a large number of cases, for cases involving small amounts of money and for cases involving large amounts of money. In part, this scalability is inherited from the system of incentivized judging in Part I. Because formal procedures are less necessary with incentivized judging than with traditional adjudication, and perhaps even less necessary with the information market, the information market may reduce the minimum fixed cost associated with an adjudication relative to traditional adjudication. Just as important, the elimination of the need to hire judges (other than those who will hear the randomly selected cases) makes it straightforward to create quickly adjudicative systems involving very large number of cases. Creating administrative bureaucracies to handle traditional adjudication may be far more cumbersome when it becomes necessary to hire large numbers of judges.

Third, the information market approach may be superior to incentivizing judges where some parties other than the litigants may already have good information about a particular case, or where multiple parties might have information that the litigants might not find in a traditional adjudicative process. The information market approach gives those with information incentives 
to participate in the process. This could be especially useful if information about a case were widely distributed.

The information market should be efficient even if no third party initially possesses any information about the case. In such cases, there may well be only a single predictor, especially if the cost of becoming sufficiently acquainted with a case to improve upon the prediction of the initial predictor is higher than the expected benefit. If that is so, then the market effectively works like a scoring rule for the first predictor. ${ }^{19}$ Because that first predictor would still be competing against the first predictor in other cases, the first predictor would retain an incentive to make an accurate prediction of the case outcome. In these circumstances, the information market becomes a privatized version of the incentivized judging model of Part I, with the private provider of adjudication services selected in the auction as the first predictor.

\section{CONCLUSION}

Neither an adjudicative system providing monetary incentives for judges nor a system that accomplishes adjudication with a market mechanism is necessarily cheaper than traditional adjudication. Because of the uncertainty that judges and participants will face over the income that they can earn, these systems could even be more expensive than a traditional adjudicative system that pays judges a fixed salary. Nonetheless, these systems may be particularly useful in adjudicative contexts in which there is a high danger and concern about idiosyncratic judicial preferences affecting substantive results. Because incentives reduce idiosyncratic judging, they may make more feasible adjudicative systems without procedural formalities or rule-bound systems, and informality itself may produce cost savings. An information market may be a particularly useful way of resolving large numbers of small claims.

Market-based judging may be most useful to enable adjudicative programs that would be infeasible with traditional adjudicative approaches. Suppose, for example, that a government wished to offer a fund for trade adjustment assistance, but the circumstances of those affected by trade varied so much that it would not be possible to craft rules that would calculate the damages from free trade that individuals suffered with acceptable accuracy. The government might be

\footnotetext{
${ }^{19}$ Indeed, this is the central reason for constructing an information market in accordance with the algorithm above, rather than as an information market involving trading of securities. In information markets based on trading of securities, low liquidity may limit market accuracy. See Hanson (2003).
} 
hesitant to create a bureaucracy to handle such claims, especially if individual agency adjudicators were expected to rule inconsistently. An information market, supplemented by an agency assigned to hear a small percentage of claims, might provide a solution. The government could specify the percentage of the fund that would be used to subsidize the information market, and claimants could receive shares in the remainder of the fund based on the awards determined by the information market. Even a relatively small subsidy, perhaps amounting to a few dollars per claim, could accomplish at least a quick-and-dirty distribution that might not be possible with a more traditional approach.

\section{References}

Abramowicz, Michael. 2004. Information Markets, Administrative Decisionmaking, and Predictive Cost-Benefit Analysis. University of Chicago Law Review. 71:933.

Amar, Akhil Reed. 1995. Lottery Voting: A Thought Experiment. 1995 U. Chi. Legal F. 193.

Berg, Joyce et al. 2000. Results from a Dozen Years of Election Futures Markets Research. http://www.biz.uiowa.edu/iem/archive/BFNR_2000.pdf.

Chen, Kay-Yut and Charles R. Plott. 2002. Information Aggregation Mechanisms: Concept, Design and Implementation for a Sales Forecasting Problem. California Institute of Technology Social Science Series. Working paper No. 1131.

Choi, Stephen J. and G. Mitu Gulati. 2004. Choosing the Next Supreme Court Justice: An Empirical Rating of Judicial Performance. UC Berkeley Public Law Research Papers. Working paper no. 141.

Clemen, Robert T. 2002. Incentive Contracts and Strictly Proper Scoring Rules. Test. 11:167.

Coons, John E. 1964. Approaches to Court Imposed Compromise: The Uses of Doubt and Reason. Northwestern University Law Review. 58:750.

Drahozal, Christopher R. 1998. Judicial Incentives and the Appeals Process. SMU Law Review. 51:469.

Forsythe, Robert et al. 1992. Anatomy of an Experimental Political Stock Market. American Economic Review. 82:1142. 
Grofman, Bernard. 1978. Judgmental Competence of Individuals and Groups in a Dichotomous Choice Situation: Is a Majority of Heads Better Than One? Journal of the Mathematics Society. $6: 47$.

Hanson, Robin. 2003. Combinatorial Information Market Design. Information System Frontiers. 5:103.

Hanson, Robin. 1995. Could Gambling Save Science? Encouraging an Honest Consensus. Social Epistemology. 9:3.

Hanson, Robin and Ryan Oprea. 2004. Manipulators Increase Information Market Accuracy. Unpublished manuscript, available at http://hanson.gmu.edu/biashelp.pdf.

Kornhauser, Lewis A. and Lawrence G. Sager. 1986. Unpacking the Court. Yale Law Journal. 96:82.

Milgrom, Paul and John Roberts. 1986. Relying on the Information of Interested Parties. Rand Journal of Economics. 17:18.

Posner, Richard A. 1993. What Do Judges and Justices Maximize? (The Same Thing Everybody Else Does). Sup. Ct. Econ. Rev. 1:14.

Shavell, Steven. 2004. On Discretion in the Application of Rules. American Law \& Economics Association Annual Meetings. Working paper 50.

Winkler, Robert L. 1969. Scoring Rules and the Evaluation of Probability Assessors. Journal of the American Statistical Association. 64:1073. 